\title{
The performance of the Nguni, Afrikander and Bonsmara cattle breeds in developing areas of Southern Africa
}

\author{
E. Collins-Lusweti* \\ University of North West, School of Agriculture, P Bag X2046, Mmabatho, 2735, South Africa. \\ *Present Address: University of Zululand, P Bag X1001, Kwa Dlangezwa, 3886 \\ Email:ecollins@pan.uzulu.ac.za
}

\section{Introduction}

The importance of indigenous livestock rests both in their adaptation and in their local availability and abundance. Among the characteristics attributed to indigenous African cattle, especially the zebus and their derivatives are tolerance to climatic stresses, especially to heat, genetic adaptation to poor quality forages and resistance to pest and diseases. As a result of natural selection, indigenous cattle (Sanga breeds) which evolved in this part of Africa have become adapted to the prevailing conditions and have a most important role to play in a successful animal agriculture in developing areas of Southern Africa (Maree \& Casey, 1993). This paper is a report of a study on the Nguni, Afrikaner and Bonsmara breed performance in developing areas of Southern Africa during the long 1989-92 drought period.

\section{Materials and Methods}

Data collected between 1989-92 on two ranches in Ganyesa (Ranch 1) and Madikwe (Ranch 2) districts in the North West Province of South Africa were analyzed to study the performance of the Nguni, Afrikaner and Bonsmara breeds in respect of birth weight, 200-day weight, calving percentage, first and second calving intervals. The analyses of variance to estimate the breed, sire (within breed), sex and month (October, November, December and January) of birth effects were done according to Equation 1 using the Harvey (1987) computer program. There were confounding effects of breed and ranch in the data and therefore the ranch was not included in the analytical model, and because of insufficient amount of data, genetic parameters were not estimated. The calving percentages were calculated from the 1991-92 data. The grazing management on the two ranches was on natural veld with a hay supplement during winter on Ranch 1 and no hay supplement on Ranch 2. Licks were given on both ranches.

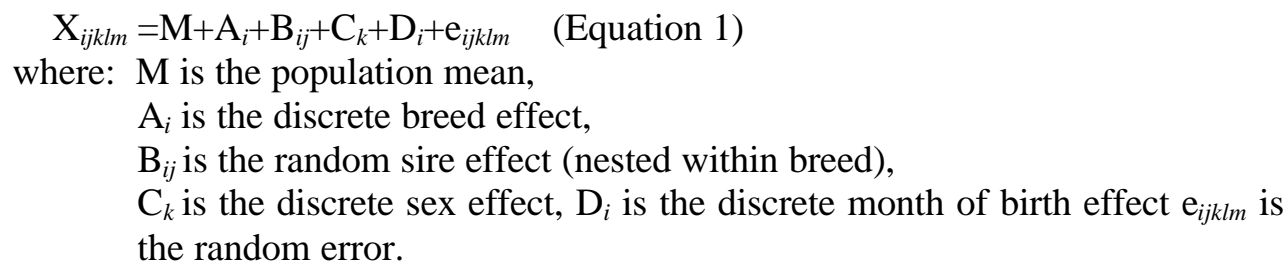

\section{Results and Discussion}

The means of traits studied are shown in Table 1. Tables 2 and 3 show the results of the analyses of variance.

Table 1: Production characteristics of indigenous breeds of Southern Africa during the drought period of 1989-1992.

\begin{tabular}{lcccccc}
\hline \multicolumn{1}{c}{ Breed } & Number & $\begin{array}{c}\text { BWT } \\
(\mathrm{kg})\end{array}$ & WT200 $(\mathrm{kg})$ & CI $(1)$ (days) & CI (2) (days) & $\begin{array}{c}\text { Calving } \\
(\%)\end{array}$ \\
\hline Nguni & 125 & 30.3 & 135.6 & 474 & 454 & 87 \\
Afrikaner & 63 & 30.2 & 173.6 & 441 & 382 & 69 \\
Bonsmara & 92 & 31.1 & 150.6 & 685 & 445 & 70 \\
\hline
\end{tabular}


(C) South African Society of Animal Science

Short paper and poster abstracts: $38^{\text {th }}$ Congress of the South African Society of Animal Science

Table 2: Analysis of variance for Birth Weight

\begin{tabular}{lccc}
\hline \multicolumn{1}{c}{ Source } & DF & MS & F \\
\hline Breed & 2 & 13.1 & $* *$ \\
Sire (within breed) & 10 & 90.6 & $* *$ \\
Sex & 1 & 549.8 & $* *$ \\
Month of Birth & 4 & 119.2 & \\
Remainder & 262 & 22.3 & \\
\hline$* * \mathrm{P}<0.01$ & & &
\end{tabular}

Table 3: Analysis of variance for 200-Day weight

\begin{tabular}{lccc}
\hline Source & DF & MS & F \\
\hline Breed & 2 & 28650 & $* *$ \\
Sire (within Breed) & 10 & 23018 & \\
Sex & 1 & 1522 & \\
Month of birth & 4 & 3047 & \\
Remainder & 262 & &
\end{tabular}

All three indigenous breeds survived the long drought and their performance in the traits studied were above average considering the low management inputs on the two ranches. These breeds play an important role in beef cattle production in the extensive bushveld farming areas of Southern Africa. The highly significant $(\mathrm{P}<$ $0.01)$ variance between sires within breed suggests that genetic improvement programs would lead to higher birth weights and 200-day weights. This study suggests that under extreme conditions the Afrikaner may outperform the Bonsmara breed.

\section{References}

Harvey, W.R. 1987. Users guide for LSMLMW least squares and muximum likelihood computer program. Ohio State University, Ohio USA.

Maree, C \& Casey, N.H., 1993. Livestock Production Systems. Agri Development Foundation, Brooklyn, South Africa. 